\title{
Creatine Kinase MB
}

National Cancer Institute

\section{Source}

National Cancer Institute. Creatine Kinase MB. NCI Thesaurus. Code C122778.

An isoenzyme complex comprised of a heterodimer of creatine kinase M-type and Btype. 